\title{
Functional tricuspid pathology: To treat or not to treat? That is the question
}

\author{
Gilles D. Dreyfus, MD, FRCS, FESC
}

\author{
From the Cardiothoracic Center of Monaco, Monte Carlo, Monaco. \\ Disclosures: Author has nothing to disclose with regard to commercial support. \\ Received for publication Feb 22, 2017; accepted for publication March 3, 2017; available ahead of print March 30, \\ 2017. \\ Address for reprints: Gilles D. Dreyfus, MD, FRCS, FESC, Cardiothoracic Center of Monaco, 11 bis, Ave d'OS- \\ TENDE, 98000 Monaco (E-mail: gdreyfus@ccm.mc). \\ J Thorac Cardiovasc Surg 2017;154:123-4 \\ 0022-5223/\$36.00 \\ Copyright (C) 2017 by The American Association for Thoracic Surgery \\ http://dx.doi.org/10.1016/j.jtcvs.2017.03.015
}

Functional tricuspid pathology (FTP) has been and is still considered as a treatment for tricuspid regurgitation (TR), which is only of concern if severe. Otherwise it is ignored. We are among those who consider FTP a relevant issue that could influence early and late outcomes. We brought up, in a systematic fashion, that annular dilatation should be considered as much as, if not more than, TR grading. The message was quite simple and advocated for treating annular dilatation rather than TR. From this initial study beginning in 1989 and lasting until $2001,{ }^{1}$ we concluded that:

- Tricuspid annular dilatation is more reliable than regurgitation because it is more consistent;

- TR is an unreliable parameter because it depends on many factors, mainly preload, afterload, and right ventricular function;

- TR is an ongoing process that, despite treatment of leftsided diseases, would worsen by itself in about $30 \%$ of cases during a follow-up period of 5 to 15 years; and

- Treating annular dilatation beyond a given size improves functional status, and there is a trend toward better survival when compared with a group of patients who did not receive tricuspid annuloplasty, irrespective of TR severity. Our study had many weaknesses, mainly the threshold value of the tricuspid annulus diameter at $70 \mathrm{~mm}$ measured intraoperatively on an arrested heart. Another weakness was that all etiologies were mixed up; however, $70 \%$ of patients had degenerative mitral regurgitation. The mean follow-up was $4.8 \pm 2.9$ years and perhaps too short to draw proper conclusions. Nevertheless, many publications reinforced our concept, including Chikwe and colleagues from New York, ${ }^{2}$ Dion from Leiden, ${ }^{3}$ Rogers and Bolling from Michigan, ${ }^{4}$ Matsunaga and Duran from Montana, ${ }^{5}$ Benedetto and colleagues from Rome, ${ }^{6}$ and Pozzoli and colleagues from Milan. ${ }^{7}$ Even the American College of Cardiology/American Heart Association guidelines included the annular size of the tricuspid valve with a threshold diameter of $40 \mathrm{~mm}$ as a type IIa recommendation. ${ }^{8}$

In a review by Badano and colleagues, ${ }^{9}$ it is clearly stated that by quantitative method, one can only grade TR as none

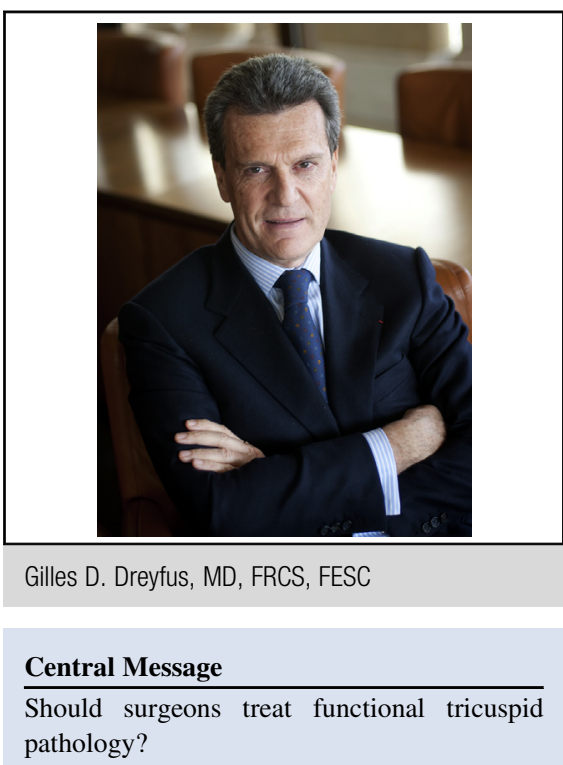

See Article page 110 .

or trivial on one hand, and severe on the other hand. In the middle sits a grey zone and moderate TR is not a welldefined entity. Three-dimensional echocardiography probably gives a better appraisal, but cannot resolve all the remaining questions.

Only a study by Yilmaz and colleagues ${ }^{10}$ supported the concept that there was no evolution of moderate/severe TR if the condition was left untreated during mitral valve repair in a follow-up period of 5 years in their initial cohort of 699 patients, all being degenerative. However, the data did not support their conclusion. At the beginning, 13\% of patients had $3+$ or $4+\mathrm{TR}$, and at 5 years $29.6 \%$ had a $3+$ or $4+$ TR (out of only 109 patients with complete follow-up at 5 years). They concluded that there was no spontaneous evolution. We concluded, with the same TR progression rate, that it was an ongoing disease that requires action at an early stage.

David and colleagues ${ }^{11}$ bring more data into this debate as they claim that "TR is uncommon after mitral valve repair for degenerative diseases." Their series is impressive, with 1171 patients followed-up for a mean duration of $9.1 \pm 5.3$ years but reaching up to 25 years. It is useless to discuss the limitations of this study because the authors have already done this: retrospective study, lack of data for the first decade, no core lab (which might be crucial especially for TR grading, which is so labile and 
questionable), and era effect because assessment and treatment changed significantly during the past 3 decades. We agree that we do not know much about the tricuspid pathology and that some risk factors such as left ventricular size and atrial fibrillation are obviously triggering factors. The title is very assertive: It says that there is no evolution of TR after mitral valve repair over 25 years' follow-up. Even if we do not completely agree, we have to take these data into consideration. Yet we believe that the debate sits elsewhere:

- Regurgitation grading is not reliable even in well-trained echocardiography labs;

- Regurgitation grading is labile and an increase in diuretics may change, in a few days, from a grade 4 TR into mild TR;

- Everybody, even David and colleagues, agrees that annular dilatation is an important factor that should be brought into the equation (unfortunately, no results are available in the series when taking this parameter into consideration);

- Surgical annuloplasties are not all similar (everybody agrees that the De Vega-type procedure should be abandoned) and using all of them without distinction may lead to erroneous conclusions;

- It is a great paradox to claim that annuloplasty does not improve outcomes and even worsens them, but it remains a key issue to determine if TR incidence progresses with time, and according to which criteria a tricuspid annuloplasty should be performed to avoid such progression (tricuspid annuloplasty does not bring any further operative risk and does prevent TR to occur, except when tethering is present).

This article reinforces the concept that FTP cannot be limited to TR only, that many other factors play a major role, and that we are still not handling them properly. We should stop referring only to regurgitation when mentioning
FTP and we should pay more attention to the coaptation mode, to annular function, and to right ventricular function.

Severe secondary TR is a highly lethal condition for which there are no clear guidelines to decide how and when to treat. Obviously if such a situation could be avoided, it should be. As Mack recently said in an editorial: "The harder one looks, the more one finds." 12

\section{References}

1. Dreyfus GD, Corbi PJ, Chan KMJ, Bahrami T. Secondary tricuspid regurgitation or dilatation: which should be the criteria for surgical repair? Ann Thorac Surg. 2005;79:127-32.

2. Chikwe J, Itagaki S, Anyanwu A, Adams D. Impact of concomitant tricuspid annuloplasty on tricuspid regurgitation, right ventricular function, and pulmonary artery hypertension after repair of mitral valve prolapse. J Am Coll Cardiol. 2015;65:1931-8.

3. Dion RA. Is the air in Toronto, Rochester, and Cleveland different from that in Mondon, Monaco, Leiden, Genk, Milan, and New York? J Thorac Cardiovasc Surg. 2015;150:1040-3.

4. Rogers JH, Bolling SF. Surgical approach to functional tricuspid regurgitation: should we be more aggressive? Curr Opin Cardiol. 2014;29:133-9.

5. Matsunaga A, Duran CM. Progression of tricuspid regurgitation after repaired functional ischemic mitral regurgitation. Circulation. 2005;112(9 Suppl):I453-7.

6. Bendetto U, Melina G, Angeloni E, Refice S, Roscitano A, Comito C, et al. Prophylactic tricuspid annuloplasty in patients with dilated annulus undergoing mitral valve surgery. J Thorac Cardiovasc Surg. 2012;143:632-8.

7. Pozzoli A, Elisabetta L, Vicentini L, Alfieri O, De Bonis M. Surgical indication for functional tricuspid regurgitation at initial operation: judging from long term outcomes. Gen Thorac Cardiovasc Surg. 2016;64:509-16.

8. Nishimura RA, Otto CM, Bonow RO, Carabello BA, Erwin JP III, Guyton RA, et al. 2014 AHA/ACC guideline for the management of patients with valvular heart disease: a report of the American College of Cardiology/American Heart Association Task Force on Practice Guidelines. J Thorac Cardiovasc Surg. 2014;148:e1-132.

9. Badano LP, Muraru D, Enriquez-Sarano M. Assessment of functional tricuspid regurgitation. Eur Heart J. 2013;34:1875-85.

10. Yilmaz O, Suri RM, Dearani JA, Sundt TM III, Daly RC, Burkhart HM, et al. Functional tricuspid regurgitation at the time of mitral valve repair for degenerative leaflet prolapse: the case of a selective approach. J Thorac Cardiovasc Surg. 2011;142:608-13.

11. David TE, David CM, Fan CPS, Manlhiot C. Tricuspid regurgitation is uncommon after mitral valve repair for degenerative diseases. J Thorac Cardiovasc Surg. 2017; 154:110-22.e1.

12. Mack M, Holmes D. Bioprosthetic valve thrombosis: the harder one looks, the more one finds. J Thorac Cardiovasc Surg. 2016;152:952-3. 